\title{
IN-SITU MICROSCOPY IN MATERIALS RESEARCH
}

\section{Leading International Research in Electron and Scanning Probe Microscopies}




\title{
IN-SITU MICROSCOPY IN MATERIALS RESEARCH
}

\section{Leading International Research in Electron and Scanning Probe Microscopies}

\author{
edited by \\ PRATIBHA L. GAI \\ Central Research and Development \\ DuPont Wilmington, Deleware, USA
}

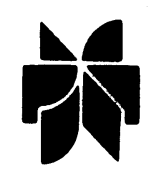

Springer Science+Business Media, LLC 


\section{Library of Congress Cataloging-in-Publication Data}

In-situ microscopy in materials research : leading international research in electron and scanning probe microscopies / edited by Pratibha L. Gai.

$$
\text { p. } \mathrm{cm} \text {. }
$$

Includes bibliographical references and index.

ISBN 978-0-7923-9989-6 ISBN 978-1-4615-6215-3 (eBook)

DOI 10.1007/978-1-4615-6215-3

1. Materials--Microscopy. 2. Electron microscopy. 3. Scanning probe microscopy. I. Gai, Pratibha L., 1948-

TA417.23.1524 1997

620.1'127--dc21

97-26282

CIP

Copyright $\odot 1997$ by Springer Science+Business Media New York Originally published by Kluwer Academic Publishers in 1997 Softcover reprint of the hardcover 1st edition 1997

All rights reserved. No part of this publication may be reproduced, stored in a retrieval system or transmitted in any form or by any means, mechanical, photo-copying, recording, or otherwise, without the prior written permission of the publisher, Springer Science+Business Media, LLC.

Printed on acid-free paper.

Cover Illustration: Direct high resolution electron microscopy image of a gold on carbon test sample, showing a gold particle with twin defects and $\sim 2.3 \AA$ (111) gold lattice plane spacings, recorded in EHREM. ( By: P.L. Gai, Central Research \& Development, Dupont). 


\section{CONTENTS}

List of Contributors $\quad$ xi

Foreword

David B. Williams xv

Preface

1. IN-SITU APPLICATIONS OF LOW ENERGY ELECTRON MICROSCOPY (LEEM) :

by E. Bauer

1. Introduction

2. Phase Transitions on Clean Surfaces

3. Segregation

4. Gas-Surface Interactions

5. Epitaxy

6. Summary

Acknowledgements and References

\section{1}



IN CULTURAL HERITAGE CONSERVATION

by Eric Doehne

1. Introduction

2. Applications

2.1 Sodium Sulfate Dynamics

2.2 Formaldehyde Corrosion

2.3 Cleaning the Sistine Chapel

3. ESEM and SEM: Operational Differences

4. ESEM/EDS Development (1990-1997) 57

$\begin{array}{ll}4.1 \quad \text { Dynamic Imaging System } & 57\end{array}$

4.2 Still Image System $\quad 58$

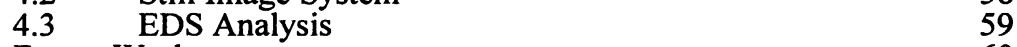

5. Future Work

Acknowledgements and References

4. INTRINSIC POINT DEFECT CLUSTERING

IN Si: A STUDY BY HVEM AND HREM

IN-SITU ELECTRON IRRADIATION

by Ludmila Fedina, Anton Gutakovskii Alexander Aseev, Joseph Van Landuyt and Jan Vanhellemont

1. Introduction

63

2. Experimental Details $\quad 65$

3. Results and Discussion $\quad 66$

$3.1 \quad$ Point Defect Clustering $\quad 66$

4. Conclusion $\quad 91$

Acknowledgements and References $\quad 91$

5. IN-SITU OBSERVATION AND QUANTITATIVE ANALYSIS OF ELECTROMIGRATION VOID DYNAMICS

by Richard Frankovic and Gary H. Bernstein

1. Introduction

Sample Fabrication and In-Situ Test Technique $\quad 96$

3. Single Void Behavior 99

3.1 Direct Void Shape Changes $\quad 99$

3.2 Secondary, Induced Voids and Hillocks 103 
4. Void-Void Interactions 108

4.1 Qualitative Results 110

$\begin{array}{ll}4.2 \quad \text { Quantitative Results } & 110\end{array}$

5. Void-Hillock Interactions 117

5.1 Qualitative Results 119

5.2 Quantitative Results 120

6. Summary and Conclusions 120

Acknowledgements and References $\quad 122$

6. ENVIRONMENTAL HIGH RESOLUTION ELECTRON MICROSCOPY (EHREM) IN MATERIALS SCIENCE

by Pratibha L. Gai and Edward D. Boyes

1. Introduction

124

2. Experimental: In-Situ Controlled Environmental High Resolution Transmission EM (EHREM) Development for Gas-Solid Reactions on the Atomic Scale Applications

3.1 Gas Molecule - Solid Surface Interactions 128

3.2 Silica based Ceramics

131

131

Chemically Stabilized Cristobalite Ceramics

3.3 EHREM of Complex Catalysts:

4. Conclusions

Acknowledgements and References

7. IN-SITU TRANSMISSION ELECTRON MICROSCOPY OF THIN FILM GROWTH

by J. Murray Gibson

1. Introduction

2. Role of TEM in Studies of Thin Film Growth

3. Instrumental Approaches

4. Some Results

165

5. Conclusions

Acknowledgements and References

8. HREM IN-SITU EXPERIMENT AT VERY HIGH TEMPERATURES

\section{by Takeo Kamino and Hiroyasu Saka}

1. Introduction

2. Specimen-Heating Holders 
3. Electron Microscope 177

4. HREM Observation of Si Particle just below the Melting Point 179

$\begin{array}{ll}\text { 5. Formation of SiC through Solid State Chemical Reactions } & 181 \\ \text { between Si and Graphite } & 181\end{array}$

$\begin{array}{ll}\text { between Si and Graphite } & 181 \\ 5.1 \quad \text { Specimens } & 181\end{array}$

5.2 Results and Discussion $\quad 181$

6. Sintering of SiC Crystals $\quad 186$

7. Surface Reconstruction of Au-deposited Si 191

$\begin{array}{lll}7.1 & \text { Specimens } & 191\end{array}$

7.2 Results and Discussion 191

Acknowledgements and References $\quad 199$

9. IN-SITU REM AND TEM STUDIES OF HOMO AND HETERO-EPITAXY ON Si SURFACES

by Hiroki Minoda and Katsumichi Yagi

1. Introduction

2. Experimental 204

$2.1 \quad$ General Remarks on REM and TEM 204

2.2 Sample Preparation 204

3. Results and Discussion 206

$3.1 \quad$ Growths of Si on Si (111) Surfaces 206

3.2 Growths of Ge on Si (111) Surfaces 208

$\begin{array}{ll}3.3 \quad \text { Growths of Ge on } \mathrm{Si}(001) \text { Surfaces } & 215\end{array}$

4. Conclusions 223

$\begin{array}{ll}\text { References } & 223\end{array}$

10. ATOMIC-SCALE FABRICATION OF METAL SURFACES BY ADSORPTION AND

CHEMICAL REACTION

by Ken-ichi Tanaka, Yuji Matsumoto, Takaya Fujita and Yuji Okawa

1. Introduction 226

2. Fabrication of Metal Surfaces by Physical Processes 228

3. Fabrication of Metal Surfaces by Chemical Reaction 240

4. Nano-meter Scale Patterning by Chemical Reactions 251

References $\quad 259$

11. HIGH TEMPERATURE DYNAMIC BEHAVIOR

OF SILICON SURFACES STUDIED BY

SCANNING TUNNELING MICROSCOPY (STM) 263

by Hiroshi Tokumoto 
1. Introduction 263

2. High Temperature UHV-STM System 264

3. Hydrogen Desorption Process on Si (111) Surface 264

4. (7x7) - (1x1) Phase Transition on Si (111) Surface 271

5. Step Shifting under dc Electric Fields 275

$\begin{array}{ll}\text { 6. Conclusions } & 280\end{array}$

$\begin{array}{ll}\text { Acknowledgements and References } & 281\end{array}$

12. DYNAMIC OBSERVATION OF VORTICES IN SUPERCONDUCTORS USING ELECTRON WAVES

\section{by Akira Tonomura}

1. Introduction

2. Experimental Method 284

2.1 Interference Microscopy 284

$\begin{array}{lll}2.2 & \text { Lorentz Microscopy } & 287\end{array}$

3. Observation of Superconducting Vortices 288

$\begin{array}{lll}3.1 & \text { Superconducting Vortices Observed by } & 288 \\ \text { Interference Microscopy } & 288\end{array}$

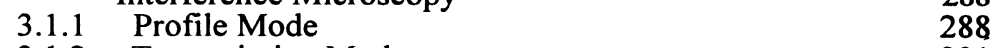

$\begin{array}{ll}3.1 .2 & \text { Transmission Mode } \\ 291\end{array}$

$\begin{array}{lll}3.2 & \text { Superconducting Vortices Observed by Lorentz } & \\ & \text { Microscopy } & 293\end{array}$

3.3 Observation of Vortex Interaction with Pinning Centers 294

3.3.1 Surface Steps 295

$\begin{array}{ll}\text { 3.3.2 Irradiated Point Defects } & 296\end{array}$

4. Conclusion $\quad 298$

$\begin{array}{ll}\text { References } & 299\end{array}$

13. TEM STUDIES OF SOME STRUCTURALLY FLEXIBLE SOLIDS AND THEIR ASSOCIATED PHASE TRANSFORMATIONS

\section{by Ray L. Withers and John G. Thompson}

$\begin{array}{ll}\text { 1. Introduction } & 301\end{array}$

2. Tetrahedrally Corner-Connected Framework Structures 302

3. Tetragonal $\alpha-\mathrm{PbO} \quad 311$

$\begin{array}{ll}\text { 4. Compositionally Flexible Anion-Deficient Fluorites } & 311 \\ \text { and the "Defect Fluorite" to C-type Sesquioxide Transition } & 320\end{array}$

5. Summary and Conclusions 327

Acknowledgements and References $\quad 327$

Author Index 331

$\begin{array}{ll}\text { Subject Index } & 333\end{array}$ 


\section{List of Contributors}

\section{A. ASEEV}

Institute of Semiconductor Physics, Russian Academy of Sciences

Novosibirsk, 630090, pr.ac., Lavrentjeva 13, RUSSIA

\section{E. BAUER}

Department of Physics and Astronomy, Arizona State University Tempe, AZ 85287-1504, U.S.A.

\section{G. H. BERNSTEIN}

University of Notre Dame, Department of Electrical Engineering 275, Fitzpatrick Hall, Notre Dame, Indiana, IN 46556, U.S.A.

\section{E. D. BOYES}

Central Research \& Development, DuPont Experimental Station Wilmington, Delaware DE 19880-0356, U.S.A.

\section{G. D. DANILATOS}

ESEM Research Laboratory, Sydney, N.S.W 2026, AUSTRALIA

\section{E. DOEHNE}

The Getty Conservation Intitute, Los Angeles

California 90049-1684, U.S.A.

\section{FEDINA (a,b)}

(a) Institute of Semiconductor Physics, Russian Academy of Sciences Novosibirsk, 630090, pr.ac., Lavrentjeva 13, RUSSIA

(b)University of Antwerpen, RUCA EMAT, Groenenborgerlaan 171, B-2020, Antwerp, BELGIUM

\section{R. FRANKOVIC}

University of Notre Dame, Department of Electrical Engineering, 275, Fitzpatrick Hall, Notre Dame, Indiana, IN 46556, U.S.A. 


\section{T. FUJITA}

Institute of Solid State Physics, University of Tokyo

7-22-1, Roppongi, Minato-ku, Tokyo 106, JAPAN

P. L. GAI

Central Research and Development, Science and Engineering Laboratories

DuPont, Experimental Station, Wilmington, DE 19880-0356, U.S.A.

\section{J. M. GIBSON}

University of Illinois, Materials Research Laboratory

104, S. Goodwin Avenue, Urbana, IL 61801, U.S.A.

\section{A. GUTAKOVSKII}

Institute of Semiconductor Physics, Russian Academy of Sciences

Novosibirsk, 630090, pr.ac., Lavrentjeva 13, RUSSIA

\section{T. KAMINO}

Techno-Research Laboratory, Hitachi Instruments Engineering Co. Ltd., 882, Ichige, Hitachinaka, Ibaraki, 312, JAPAN

\section{MATSUMOTO}

Institute of Solid State Physics, University of Tokyo 7-22-1, Roppongi, Minato-ku, Tokyo 106, JAPAN

\section{H. MINODA}

Department of Physics, Tokyo Institute of Technology Oh-Okayama, 2-12-1, Meguro-ku, Tokyo 152, JAPAN

\section{Y. OKAWA}

Institute of Solid State Physics, University of Tokyo

7-22-1, Roppongi, Minato-ku, Tokyo 106, JAPAN

\section{H. SAKA}

Department of Quantum Engineering, Nagoya University

Furo-Cho, Chikusa-ku, Nagoya, 464-01, JAPAN 


\section{K. TANAKA}

Institute of Solid State Physics, University of Tokyo

7-22-1, Roppongi, Minato-ku, Tokyo 106, JAPAN

\section{J. G. THOMPSON}

Research School of Chemistry, Australian National University

Canberra , A.C.T. 0200, AUSTRALIA

\section{H. TOKUMOTO}

Joint Research Center for Atom Technology, (JRCAT), National Institute for Advanced Interdisciplinary, Research (NAIR),

Higashi 1-1-4, Tsukuba, Ibaraki-305, JAPAN

\section{A. TONOMURA}

Advanced Research Laboratory, Hitachi Ltd.

Hatoyama, Saitama, 350-03, JAPAN

\section{J. VAN LANDUYT}

University of Antwerpen, , RUCA EMAT, Groenenborgerlaan 171,

B-2020, Antwerp, BELGIUM

J. VANHELLEMONT (c,d)

(c) IMEC, Kapeldreef 75, B3001, Leuven, BELGIUM

(d) Present address: Wacker Siltronic, A.G., P.O. Box 1140, D-84479, Burghausen, GERMANY

\section{R. L. WITHERS}

Research School of Chemistry, Australian National University

Canberra, A.C.T. 0200, AUSTRALIA

\section{K. YAGI}

Department of Physics, Tokyo Institute of Technology

Oh-Okayama, 2-12-1, Meguro-ku, Tokyo 152, JAPAN 


\title{
FOREWORD
}

\begin{abstract}
A fundamental limitation of almost all microscopy investigations of materials is that the images are static and taken when the specimen is at room temperature. More particularly, in electron microscopy (EM), the technique which constitutes most of this text, the specimen is also in a high or ultra-high vacuum and under intense radiation. Unfortunately, all these conditions rarely represent the treatment that the material has received during its processing to final form, or the conditions it will suffer during its service life. Consequently, we microscopists often make assumptions about a material's ability to retain its high-temperature structure and chemistry during rapid cooling to room temperature; also we generally ignore surface effects in thin specimens and assume that no changes take place during bombardment with intense radiation. Obviously all these assumptions can be seriously wrong in many practical studies and this text presents a broad overview of methods by which some or all of these limitations can be overcome.
\end{abstract}

Specifically in the case of EM, in-situ microscopy is a mature field that blossomed in the 1960s and 70s with the development of the first megavolt TEMs. These instruments had sufficient space in their specimen stages to accommodate heating, tensile and gas-reaction stages, and also were powerful enough to permit observation of specimens that were thick enough to mimic bulk behavior. However, no comprehensive review has been written in the last couple of decades, even though some of the old $\mathrm{MeV}$ microscopes continue to perform and dozens of 300-400 keV ones, well capable of in-situ studies, have been delivered in recent years. So this book represents an essential addition to the microscopists' library, because of the extraordinary instrument developments that have taken place. New microscopes and microscopies have appeared, but of equal importance are the improvements in our ability to record dynamic images with modern video/CCD cameras as well as store the images and process them digitally. Unique instruments have also been created in a few microscopy laboratories around the world, and results from several of these are described here in detail. In many cases, such instruments have been designed with very specific materials problems in mind, such as the need for extremely high temperatures to study ceramics and the combination of gas reactions with atomic resolution to understand catalysis.

Another remarkable development, that of environmental SEMs is properly emphasized. The ESEM has generated a wide array of related low-vacuum or variablepressure SEMs. Now we have a whole new field of materials characterization, combining our long-standing abilities to heat, cool and deform bulk specimens in the SEM with the ability to image their surfaces under significant pressure of a gas, that may also react chemically with the specimen. More recent tools such as scanning probe microscopes have been able to build on the many hardware developments in the 
xvi

EM field.

In a truly diverse field that represents one of the last technical frontiers in microscopy, this text both educates and informs the materials scientist and the microscopist with a well-chosen spectrum of chapters from internationally renowned scientists.

David B. Williams

Lehigh University

Bethlehem PA 


\section{PREFACE}

The ability to study dynamic materials directly, in-situ, close to their natural state as they undergo reactions is a very important goal in materials research and technology. In-situ microscopy under dynamic conditions with real-time monitoring of events provides information on material processes that can not be obtained directly by other methods. Material scientists who include physicists, chemists, ceramicists, biologists and conservation scientists associated with the preservation of cultural heritage, often want to know how materials behave in their true state under reacting conditions, what structural changes there are and how they affect their properties. This is because post-reaction examination of static sample (cooled to room temperature from a higher reaction temperature, or taken out of its natural reaction environment) is not often representative of the dynamic system. Striking breakthrough developments in in-situ microscopy instrumentation and applications are making the dream of observing materials directly and dynamically, a reality. The purpose of this book is to provide an authoritative and informative account of the interdisciplinary developments and applications of in-situ microscopy in materials and surface science research. The chapters are written by renowned international scientists who have pioneered many of these outstanding fields of research at leading laboratories in the world. They address fundamental materials and process issues in semiconductor technology, ceramics, superconductors, integrated circuits, heterogeneous catalysis, polymeric materials, biological research and conservation science. Major and novel opportunities in materials research have continued to evolve directly as a consequence of in-situ microscopy studies.

In this regard, we have attempted to incoroporate several fields of in-situ microscopy, namely, environmental scanning electron microscopy (ESEM) and field emission-SEM, low energy EM (LEEM), scanning tunneling microscopy (STM), reflection EM (REM), in-situ high voltage EM (HVEM), ultra high vacuum (UHV)-TEM, environmental-high resolution transmission EM (EHREM) to study gas molecule-solid surface interactions on the atomic scale, atomic levelHREM with very high temperature holders, electron holography and Lorentz microscopy. LEEM is an important surface science technique used to image bulk surfaces with low energy electron diffraction (LEED) to study phase transitions on clean surfaces of semiconductors, segregation of impurities, gas chemisorption and molecular beam epitaxy (MBE). Striking ESEM developments highlight expanding uses of the technology in diverse fields such physical sciences, biological sciences, fibers, wet samples and describe conditions for optimum electron beam transfer from high vacuum to high pressure environments whilst preserving secondary imaging, X-ray detection and cathodoluminecsence. Practical development and applications of ESEM in the important fields of Museum and Conservation Science describe conservation studies of cultural heritage and property including the Sistine Chapel in Rome and Dead Sea Scrolls. Electromigration void nucleation and growth is a failure mechanism of integrated circuits (IC) metallization. Using in-situ SEM, void growth and interaction dynamics have been explored to study electromigration performance of IC interconnects. A 
significant approach is the in-situ studies of point defect reactions and point defect clustering during intense electron irradiation in an HVEM which are relevant to the fundamental understanding of intrinsic point defect behavior in technologically important silicon semiconductors, ion implantation and thermal oxidation. Notable EHREM development enables key studies of live gas molecule - solid surface interactions at elevated temperatures on the atomic scale. It allows access to metastable intermediate phases and local chemistry, to both surface and bulk (subsurface) microstructural changes which are often interrelated and to novel reaction mechanisms crucial to chemical processes. Diverse applications of EHREM include studies of samples in reducing / oxidizing gases or in moist environments, technologically important complex catalysts, defect structures and new ceramics. The important role of in-situ and UHV TEM in thin film semiconductor growth is elucidated allowing visualization both of the surface structure and internal film microstructure. Impressive sample holders have been developed which allow observations at near atomic resolution of reactions taking place at very high temperatures $\left(\sim 1500{ }^{\circ} \mathrm{C}\right)$. Using powerful in-situ REM and TEM methods, surface structure (atomic height steps) and dramatic surface reconstruction during semiconductor thin film growth in very wide areas, as well as interface dynamics between substrates and overgrowth films have been elucidated. Elegant developments in scanning tunneling microscopy (STM) studies describe a high temperature-UHV-STM, and atomic scale fabrication of metal surfaces by adsorption and chemical reaction. The high tempearture UHV-STM is used to study dynamic behavior of Si (111) surfaces upto $950^{\circ} \mathrm{C}$. The utility of STM for exploration of surface restructuring describes reactions between the STM tip and the sample surface where selective atom-transportation via chemical reaction to a desired area on the surface known as "atom-painting" is viable, leading to important new concepts and possibilities of designing fundamental new surfaces and atomicscale patterning. The development of "coherent" field emission electron beam has been utilized to directly and dynamically observe superconducting vortices, including magnetic lines of force by in-situ holography and dynamics of vortices by Lorentz microscopy. The unique role of electron diffraction is elucidated in studies of phase transformations in structurally flexible silica based ceramic solids including in revealing the existence of highly structured diffuse intensities in reciprocal space. The chapters are arranged in an alphabetical order.

It is hoped that the book will be a rich source of information to both the newcomers and practising scientists in this rapidly expanding field of in-situ microscopy of dynamic processes and their relationship to material properties.

I am most grateful to all the contributors of this book for their excellent and elegant chapters. As editor, it has been my great privilege and pleasure to work with the internationally eminent researchers. I would like to express my thanks to John Bodt who has been responsible for the successful realization of this project and to Kluwer Academic Publishers for the opportunity. I am deeply indebted to Urmila Chandr and Laxman for the encouragement. 